\title{
What is the available evidence concerning relative performance of different designs of mixed-species plantings for smallholder and community forestry in the tropics? A systematic map protocol
}

Huong Nguyen ${ }^{1,2^{*}}$, John Herbohn ${ }^{1,2}$, Jessica Clendenning ${ }^{3}$, David Lamb ${ }^{4}$, Wolfram Dressler ${ }^{5}$, Jerry Vanclay 1,6 and Jennifer Firn ${ }^{7}$

\begin{abstract}
Background: There has been growing interest in mixed species plantation systems because of their potential to provide a range of socio-economic and bio-physical benefits which can be matched to the diverse needs of smallholders and communities. Potential benefits include the production of a range of forest products for home and commercial use; improved soil fertility especially when nitrogen fixing species are included; improved survival rates and greater productivity of species; a reduction in the amount of damage from pests or disease; and improved biodiversity and wildlife habitats. Despite these documented services and growing interest in mixed species plantation systems, the actual planting areas in the tropics are low, and monocultures are still preferred for industrial plantings and many reforestation programs because of perceived higher economic returns and readily available information about the species and their silviculture. In contrast, there are few guidelines for the design and management of mixed-species systems, including the social and ecological factors of successful mixed species plantings.

Methods: This protocol explains the methodology used to investigate the following question: What is the available evidence for the relative performance of different designs of mixed-species plantings for smallholder and community forestry in the tropics? This study will systematically search, identify and describe studies related to mixed species plantings across tropical and temperate zones to identify the social and ecological factors that affect polyculture systems. The objectives of this study are first to identify the evidence of biophysical or socio-economic factors that have been considered when designing mixed species systems for community and smallholder forestry in the tropics; and second, to identify gaps in research of mixed species plantations. Results of the study will help create guidelines that can assist practitioners, scientists and farmers to better design mixed species plantation systems for smallholders in the tropics.
\end{abstract}

Keywords: Polyculture, Mixture, Reforestation, Forestry economics, Social forestry

\footnotetext{
* Correspondence: h.nguyen22@uq.edu.au

${ }^{1}$ Forest Industries Research Centre, University of the Sunshine Coast,

Maroochydore, QLD 4558, Australia

${ }^{2}$ School of Agriculture and Food Sciences, The University of Queensland, St

Lucia, QLD 4072, Australia

Full list of author information is available at the end of the article
}

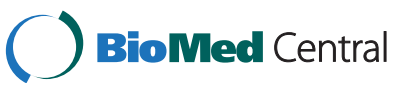

(C) 2015 Nguyen et al.; licensee BioMed Central. This is an Open Access article distributed under the terms of the Creative Commons Attribution License (http://creativecommons.org/licenses/by/4.0), which permits unrestricted use, distribution, and reproduction in any medium, provided the original work is properly credited. The Creative Commons Public Domain Dedication waiver (http://creativecommons.org/publicdomain/zero/1.0/) applies to the data made available in this article, unless otherwise stated. 


\section{Background and objectives}

Over the past two decades, there has been rising interest in planting mixtures of tree species to establish plantations that provide multiple services in the tropics. Despite this interest, the proportion of new plantings which are mixtures of species is low, relative to the area of monoculture plantations established. Monocultures offer significant economic benefits and have been preferred in large-scale 'industrial' plantation development in the tropics. However, there has been a shift to smallholder and community forestry in the tropics, along with a requirement of many national reforestation programs to use mixtures, especially involving combinations of native species for which there is often little comprehensive information. To date, there have been few formal guidelines or principles synthesized to assist the design and establishment of mixed-species plantation systems that recognize the diverse needs of rural smallholders and communities. This systematic map aims to describe the available evidence on mixed species plantation systems and identify where future research is needed.

Mixed-species plantings are well suited to smallholder and community forestry for a number of reasons. Some mixed-species plantations have been recognized as more successful than monocultures in enhanced biomass production and carbon sequestration, improved soil nutrients, reduced damage from pest or disease, and improved financial benefits [1]. Depending on the primary objective of planting, each plantation could have a different suite of tree species suitable for a variety of needs (e.g. for wood production, protection, fuel wood and folder, or landscape) [2]. Successful mixed plantations that have a similar or greater productivity to monocultures of the same species, are likely to have greater niche complementarity between species or even ecological facilitation, contrasting phenologies, or complementary root or canopy architectures [3-5]. Stratified mixtures that combine rapidly growing upper canopy species with slow-starting and shade-tolerant species are likely to exhibit greater total productivity than pure stands only involving shade-intolerant species [6, 7]. Mixed stands can also improve the survival and growth of a species in nutrient-poor soils [8], especially with the inclusion in the mix of a nitrogen-fixing species.

Mixtures can also provide some financial benefits that are attractive to smallholders and communities because they may provide a more diverse range of livelihood products (i.e., fruit, crops, resin, early timbers of shortlived species or valuable timbers of long-lived species) [9-11], which may help farmers diversify their subsistence and capital investment. Mixtures can also generate financial returns in both the short-term (from harvesting faster growing species) and in the longer term (from harvesting slower-growing but more valuable species). The diversity of species with differing traits also means mixtures can be more resilient in the face of ecological disturbance and may be better able to withstand fluctuations of market prices [12].

Mixed-species plantations also offer more biodiversity and ecological benefits for smallholder communities compared to monoculture plantations. For example, plantations mixtures with nitrogen fixing species may improve soil fertility and nutrient cycling because multispecies have a greater ability to access and conserve nutrients [13-15]. Mixtures can sometimes limit damage from pests and diseases because susceptible trees species are hidden in among the mixtures or natural enemies of pests are encouraged $[10,15,16]$. Mixtures also support a greater variety of wildlife and contribute to the restoration and maintenance of higher biodiversity within landscapes [17]. Complex plantation mixtures of 5-70 species have been used for the ecological restoration of degraded lands; these large numbers of species of different successional stages are combined to reduce the need for a series of sequential plantings [18].

Mixed-species systems are a form of reforestation and the factors that drive their success or failure are likely to be similar, at least in part, to other forms of reforestation. Le et al. [19] have undertaken a comprehensive review of the factors that drive reforestation success in tropical developing countries. These drivers are grouped into technical/ biophysical drivers; socio-economic drivers; institutional, policy and management drivers; and reforestation project characteristics. We apply a similar framework in describing the current literature around mixed species systems in community forestry, especially noting where there are research gaps or missing information that are important to better understand successful mixed species systems.

A key necessity for designing mixed species stands is the need to combine species that are complementary in characteristics such as shade tolerance, height growth rate, crown structure, foliar and root phenology and root depth [20]. Thus, a mixed-species plantation may contain shortlived species with long-lived species, fast-growing with slower-growing species or shade-tolerant and shadeintolerant species able to occupy different positions in the forest canopy. Such mixtures of species can potentially reduce competition for light and increase overall light interception $[6,21-24]$. In such cases, species requirements are more likely to differ as species will have varying resource needs and therefore occupy different niche space, allowing them to continue to grow complimentarily.

Among others, Piotto [17] undertook a comprehensive review of factors affecting the performance of species within mixtures and compared growth in monocultures and mixtures across regions and species. However that study was limited in terms of the number of factors considered (i.e. stand composition and the presence of nitrogenfixing tree species). A number of additional studies have been published which may shed further light on the topic. 
This systematic map will identify and describe current knowledge of mixed species systems to distil guidelines to assist in the design of mixed species plantations for smallholder and community forestry. Based on a search of the literature related to mixed species forestry systems in temperate and tropical regions by a diverse team of experts, we will collect evidence on alternative ways to design mixed-species systems that will be of broad interest and application in tropical regions. As such, this systematic map addresses the main question: What is the available evidence for the relative performance of different designs of mixed-species plantings for smallholder and community forestry in the tropics?

In answering this question, the map has three subobjectives addressed through collecting and surveying relevant literature. The first sub-objective involves appraising the ecological issues and to:

(1) Identify the available evidence of key biological factors to be considered when designing mixed species plantings in the humid tropics, including species-site matching, and inter and intra-species interactions.

Compared to the literature on the growth of mixedspecies plantations, much less is known on the specific social and economic factors that are important in the design of mixed-species systems. Yet there is much in the broader literature on social and economic factors affecting reforestation that can be applied to the design of mixtures. Importantly, there is also often a mismatch between social and ecological goals of reforestation. Reforestation has either aimed to fulfil social or economic needs without reference to ecological goals, or it has had a narrow conservation aim without taking into account the social and economic needs of people [25]. As Higgs [26] has argued, good reforestation requires a view expanded beyond the technical to include historical, social, cultural, economic and political aspects. Neglecting such aspects may generate conflicts when reforestation programs are introduced in complex rural settings [27-29]. While Le et al. [19] is possibly the most comprehensive review of social factors affecting the success of reforestation in general (see diagram in Additional file 1), their work does not discuss in detail the differences between mixed-species and monocultures, nor between smallholder and community forestry across different levels of social and political organisation (People's Organisations,
Municipal Councils etc.). In recognition of these critical factors, the second sub-objective will:

(2) Identify the available evidence of key socio-economic factors to be considered when designing mixed species plantation systems.

As part of the systematic map, our final sub-objective will:

(3) Synthesise and describe the available evidence of biophysical and socio-economic factors that have been considered for mixed-species systems and identify areas where more research is needed.

The map's main PICO question elements are further summarised in Table 1.

\section{Methods}

\section{Search strategy}

The following bibliographic databases will be searched:

\section{Databases}

1) Scopus (http://www.scopus.com) [30]

2) $\mathrm{CABI}: \mathrm{CAB}$ Abstracts in Web of Science (http://www.cabdirect.org/) [31]

3) Web of Science ${ }^{\mathrm{Tm}}$ Core Collection (http://www.webofknowledge.com) [32]

4) Agricola (http://agricola.nal.usda.gov/) [33]

5) GFIS.net (http://www.gfis.net/gfis/en/en/) [34]

\section{Internet searches}

- Google Scholar (scholar.google.com) [35]

Google Scholar will be used to test the comprehensiveness of our literature search. The first 150 returned hits will be assessed and any relevant literature not already retrieved from the prior searches will be included. All search combinations, terms and dates used will be included in an appendix to the systematic map.

\section{Grey literature}

A limited selection of 'grey' literature (i.e. published and unpublished documents that do not pass through the

Table 1 Population/subject, interventions, comparators and outcomes (PICO) relevant to the systematic map

\begin{tabular}{llll}
\hline Population & Intervention & Comparison & Outcome \\
\hline $\begin{array}{l}\text { Tree plantations in the humid tropics and } \\
\text { temperate regions and the communities that }\end{array}$ & Mixed species & Forms of reforestation that include & Success indicators in biological, socio- \\
manage them. & trees & $\begin{array}{l}\text { alternative forms of mixed species } \\
\text { plantings }\end{array}$ & economic attributes in mixed species \\
\hline
\end{tabular}


scientific peer-review process) will be identified by consulting the following organizations and research institutes:

1) World Bank (www.worldbank.org) [36]

2) Asian Development Bank (www.adb.org) [37]

3) The Center for People and Forests (RECOFTC) (www.recoftc.org) [38]

4) Food and Agriculture Organization (FAO) (www.fao.org) [39]

5) Tropenbos International (www.tropenbos.org) [40]

6) International Tropical Timber Organziation (ITTO) (www.itto.int) [41]

7) World Wildlife Fund (WWF) (www.worldwildlife.org) [42]

8) French Agricultural Research Centre for International Development (CIRAD) (www.cirad.fr/en) [43]

9) Tropical Agricultural Research and Higher Education Center (CATIE) (http://www.catie.ac.cr/en/) [44]

10) University of the Philippines, Los Banos (www.uplb.edu.ph) [45]

11) Chiang Mai University (www.cmu.ac.th/index_eng.php) [46]

12) Center for International Forestry Research (CIFOR) (www.cifor.org) [47]

13) World Agroforestry Centre (ICRAF) (www.worldagroforestry.org) [48]

14) International Union of Forest Research Organizations (IUFRO) (www.iufro.org) [49]

15) Small-scale Forestry Group (http://www.iufro.org/ science/divisions/division-3/30000/30800/) [50]

16) University of South Florida (USF) (www.esf.edu) [51]

17) United States Department of Agriculture (USDA) (www.usda.gov) [52]

18) Partnership for the Tropical Forest Margins (ASB) (http://www.asb.cgiar.org/) [53]

\section{Contacts within the smallholder and community forestry field}

Recognised experts, practitioners and authors will be contacted for further recommendations on relevant unpublished material or data. A full list of the individuals consulted and the type of information collected will be included in an appendix to the systematic map.

\section{Search terms and combinations}

Searches will be conducted in English from 1980 to the present. This time period was chosen because the online databases are limited to articles that were published in journals before 1980 .

To ensure a comprehensive search for literature relevant to mixed species plantings, search terms would need to include terms related to "tree or forest", "mixed species" and "planting or plantation". The following search terms (Table 2) will be utilized in each of the online databases and web searches:

(tree" OR forest" OR agroforest" OR "agro forest" AND ("mixed species" OR polycultur" OR "two species mixture" OR "multi" species planting"" OR "species rich planting" OR rainforest" OR "mixed stand" OR mixture* OR "mixed woodlot*") AND (planting* OR plantation* OR planted OR reforest" OR afforest" OR "forest rehab" OR "forest restor*" OR nurse* OR stand" OR woodlot*).

Additionally, searches in the Scopus database will use a Field tag (TITLE-ABS-KEY) to search relevant search titles, abstracts and keywords. The search in Web of Science $^{\text {Tw }}$ Core Collection and CAB Abstracts will use Field tag (TS) to search relevant topics including titles, abstracts, author keywords and keywords.

Search results from all databases will be exported to Endnote 17 citation manager and cleaned for duplications. Remaining citations will go through a screening process at title, abstract and full text levels, guided by the inclusion/exclusion criteria explained below.

\section{Search comprehensiveness}

Thirty-five relevant studies representing different disciplines in the study of mixed species (i.e., 30 biophysical papers and 5 socioeconomic papers) were selected to test the comprehensiveness of our database searches (see citations in Additional file 2). The initial scoping searches retrieved 4866 hits from Scopus database, 4871

Table 2 Final categories of search terms, phrases and string

\begin{tabular}{|c|c|c|}
\hline \# & Main terms & Expanded terms \\
\hline 1 & Tree or forest & Tree* OR forest* OR agroforest* OR "agro forest*" \\
\hline $1 \mathrm{a}$ & Mixed species & $\begin{array}{l}\text { "Mixed species" OR polycultur* OR "two species mixture*" OR "multi* species planting*" OR "species rich } \\
\text { planting*" OR rainforest* OR "mixed stand*" OR mixture* OR "mixed woodlot*" }\end{array}$ \\
\hline 2 & Planting or plantations & $\begin{array}{l}\text { Planting* OR plantation* OR planted OR reforest* OR afforest* OR "forest rehab*" OR "forest restor*" OR } \\
\text { nurse* OR stand* OR woodlot* }\end{array}$ \\
\hline & $\begin{array}{l}\text { Region: humid tropics and } \\
\text { temperate regions }\end{array}$ & $\begin{array}{l}\text { The map will focus on designs for mixed species planting in the humid tropics. However, literature from } \\
\text { mixed species plantings in the temperate regions will be included in the map as these may be also have } \\
\text { useful information for this study. }\end{array}$ \\
\hline
\end{tabular}


hits from $\mathrm{CAB}$ Abstracts, and 6629 hits from Web of Science $^{\mathrm{TM}}$ Core Collection. As the type of journals sourced varied across databases we limited the search results to relevant research areas (i.e. Forestry OR Environmental Sciences OR Ecology OR Plant sciences OR Agriculture for the Web of Science; and "AGRI" OR "ENVI" for Scopus database; no additional filter for CAB Abstracts). This narrowed our search results to 3973 hits from Web of Science and 3936 hits from Scopus database.

To expand the search for relevant evidence, a search of grey literature will be conducted. This will include websites of major organizations and key databases conducting research on forestry as outlined above. Combinations of main search terms ("tree or forest", "mixed species", "planting or plantations") will be applied for internet or smaller database searches if the full search string is not usable on the websites.

\section{Article screening and study inclusion criteria}

In order to be included in the map's review, a study needs to fulfil each of the following criteria:

\section{Relevant subject(s)}

The study makes mention of (wood-based) multiple (at least two) tree species mixtures/plantations in humid tropics of South America, Asia, Africa and Australia and temperate regions of North America, Europe and Australia.

\section{Relevant intervention(s)}

The study considers a deliberate mixed planting of tree species.

\section{Relevant outcomes}

Success indicators related to forest performance (e.g. survival, growth, etc.), environmental attributes (e.g. vegetation structure, biodiversity, ecosystem functions) and socio-economic attributes (e.g. income, timber products, likelihood, etc.) of the mixed species plantations.

\section{Relevant study design}

Studies that document biophysical and socio-economic monitoring of a deliberate tree mixture; retrospective analyses; designed field trials; experimental and nonexperimental studies; qualitative and quantitative livelihood and economic surveys (ex-ante or ex-post); meta-analyses of mixed species plantings.

\section{Excluded studies}

Studies on fruit trees; agroforestry trials with only one tree species; studies only talking about the management of natural forests; community forestry studies involving natural forest regrowth; studies only reporting on biodiversity; studies only reporting on monocultures. Any studies that are from dry, arid regions of Africa or South America will be excluded.

Articles will be screened through a three-stage process. First, articles will be screened at title level to exclude highly irrelevant studies. Then, articles will be screened at the abstract level following the inclusion criteria. Four reviewers will do a Kappa test [54] to compare agreement before abstract screening begins, which involves each reviewer screening the same 100 articles and discussing discrepancies. The test will be repeated until an acceptable Kappa score $(>0.6)$ is obtained. When there is disagreement between reviewers, the articles will be discussed with reference to the inclusion criteria for further clarity and understanding. Then, each reviewer will combine their results to the final list of relevant articles. Articles excluded at full text will be listed in an appendix together with reasons for exclusion.

\section{Study quality assessment}

Systematic maps aim to characterize and describe the evidence base around a particular question. As such, we will aim to describe and organize the types of studies collected and methods used in tropical mixed species systems research through a general appraisal process. All studies that pass full text screening will be passed through the appraisal criteria described below, which aims to give indicators on the relative strength of the study design and rigor applied, relative to our research question. The aim of this exercise is not to comment on the study quality or exclude studies (unless irrelevant and missed in the initial screening), but instead group and describe how the studies were conducted for a clearer picture of the evidence base.

All articles included in full text assessment will be characterized on the following criteria, including:

- Presentation of clear aims

- Sample size

- Length of the study

- Type of study (e.g. primary data, meta-analysis, review)

- Type of information given on the related socio-economic outcomes (i.e., ownership, tenure, or wider community;

- Biological and socio-economic factors considered in the study

- Plantation performance; ecological and socio-economic attributes from the plantations

These criteria will be used as a proxy to show the frequency of study designs used in the literature. Further information related to the outcomes of mixed species systems are described in the data mapping process below. 


\section{Study coding}

The data categories described in Tables 3 and 4 will be applied to record information for all included studies. These categories were trailed by randomly selecting 10 biophysical papers and 4 socio-economic papers (Additional file 3). Information will be recorded in an Excel file with drop down menus used as much as possible to record the type of mixed species plantations; the main socio-economic and biophysical factors and trends; tree performance; and descriptive details about the locations. Narrative details will also be recorded to understand alternative socio-

Table 3 Categories for extracting data from biophysical literature

\begin{tabular}{|c|c|}
\hline Type of information & Description \\
\hline Types of literature & $\begin{array}{l}\text { e.g. primary data, meta-analysis, review) (if a } \\
\text { review (record date, number of citations) }\end{array}$ \\
\hline Source of literature & $\begin{array}{l}\text { e.g. Journal name or grey literature or } \\
\text { conference proceedings or book; open } \\
\text { or fee based access; availability in } \\
\text { electronic or hard copy }\end{array}$ \\
\hline Year published & $\begin{array}{l}1980 \text { - present (limited coverage prior } \\
\text { to } 1996 \text { in Scopus }{ }^{\mathrm{a}} \text { ) }\end{array}$ \\
\hline Location/country/region & where work was done \\
\hline Objective of the planting & production, ecosystem services, or both \\
\hline Scale of planting & e.g. plot, trial or operational \\
\hline $\begin{array}{l}\text { - If plot or trial, what is the } \\
\text { purpose? }\end{array}$ & $\begin{array}{l}\text { i.e., hypothesis testing, species elimination } \\
\text { trials, species complementarities/facilitation }\end{array}$ \\
\hline \multirow[t]{2}{*}{ - If Operational } & $\begin{array}{l}\text { (1) Type of ownership: (secure/insecure, } \\
\text { formal or informal tenure, private, public, } \\
\text { community, etc.) }\end{array}$ \\
\hline & $\begin{array}{l}\text { (2) Type of plantation: (i.e. mixed species } \\
\text { plantation, ecological restoration or } \\
\text { landscape plantation) }\end{array}$ \\
\hline
\end{tabular}

(3) Method of management or harvesting: (i.e., thinning, pruning or other)

\begin{tabular}{|c|c|}
\hline Age of planting & in years or range \\
\hline Establishment method & $\begin{array}{l}\text { e.g. planted, direct seeded, number of } \\
\text { species to plant }\end{array}$ \\
\hline Key species & $\begin{array}{l}\text { e.g. Pinus spp /Eucalyptus spp /Acacia } \\
\text { spp /Gmelina spp/other) includes nitrogen } \\
\text { fixer, native or exotic }\end{array}$ \\
\hline Type of products & $\begin{array}{l}\text { e.g. fuel, on-farm timber vs. for sale timber, } \\
\text { other }\end{array}$ \\
\hline Key factors investigated & $\begin{array}{l}\text { e.g. biological or socio-economic factors } \\
\text { considered in designing the study or to } \\
\text { compare types of designs }\end{array}$ \\
\hline No. of species & give number \\
\hline Outcomes measured & $\begin{array}{l}\text { e.g. yield, growth, carbon sequestration, } \\
\text { soil nutrient etc. }\end{array}$ \\
\hline Type of attributes & $\begin{array}{l}\text { e.g. ecological, economic, or social } \\
\text { attributes }\end{array}$ \\
\hline $\begin{array}{l}\text { Provision of ecosystem } \\
\text { service }\end{array}$ & $\begin{array}{l}\text { e.g. watershed protection, water yields, } \\
\text { wildlife habitat, carbon sequestration, none }\end{array}$ \\
\hline
\end{tabular}

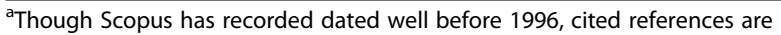
available on Scopus only from 1996 on [55]
Table 4 Categories for extracting data from socio-economic literature

\begin{tabular}{ll}
\hline Type of information & Description \\
\hline Types of literature & $\begin{array}{l}\text { e.g. primary data, meta-analysis, review) } \\
\text { (if a review (record date, number of } \\
\text { citations) } \\
\text { e.g. Journal name or grey literature or } \\
\text { conference proceedings or book; open } \\
\text { or fee based access; availability in } \\
\text { electronic or hard copy }\end{array}$ \\
& $\begin{array}{l}1980 \text { - present (limited coverage prior to } \\
1996 \text { in Scopus) }\end{array}$ \\
Year published & $\begin{array}{l}\text { where work was done } \\
\text { Location/country/region }\end{array}$ \\
$\begin{array}{l}\text { Attitudinal/decision-making } \\
\text { Financial analysis } \\
\text { (household) or economic } \\
\text { analysis }\end{array}$ & $\begin{array}{l}\text { e.g. financial and other impacts, } \\
\text { accounting/economic perspective }\end{array}$ \\
Community dynamics & organizational \& behavioural dynamics \\
Institutional/policy dynamics & \\
Other & \\
\hline
\end{tabular}

economic or biophysical factors that could affect the outcomes of mixed species plantations in the tropics.

\section{Data mapping and presentation}

We plan to provide a narrative mapping of all articles that were reviewed in full. The systematic map will first and foremost present an evidence map of the socioeconomic and biophysical trends and knowledge gaps reflected from the available literature. Descriptive statistics, to the extent that is possible, will also be used to summarise quantitative trends, map the type of articles reviewed, and highlight their relevance to the primary question. The statistical analysis will be supplemented by summary analysis of any qualitative information collected. The narrative report will be supplemented with graphs and charts which describe the frequency of study designs and durations, locations, and other biophysical factors. A searchable Microsoft Access database of included full-text articles will be made available alongside the map, which will include two spread sheets: one for biophysical and another for socio-economic studies. Each sheet will organize the studies under "humid tropical" or "temperate" forest regions. The aim is for future researchers, scientists and development professionals to use the map and database for improved designs of mixed species plantation systems for community forestry.

\section{Additional files}

Below is the link to the electronic supplementary material. 


\section{Additional file 1: Conceptual model for assessing reforestation success.}

Additional file 2: Citations used to test search comprehensiveness. Additional file 3: Test data categories to extract data from relevant citations.

\section{Competing interests}

The authors declare that they have no competing interests.

\section{Authors' contributions}

$J H$, conceived the study. JH, HN, JC, WD, DL and JV participated in an author workshop to draft project questions, eligibility criteria and discuss data extraction templates. $\mathrm{JH}, \mathrm{HN}$, and $\mathrm{JC}$, coordinated the study. $\mathrm{HN}, \mathrm{JH}$, and $\mathrm{JC}$, designed and drafted the manuscript. DL, WD, JV, and JF, provided feedback and input to manuscript. All authors read and approved the manuscript.

\section{Acknowledgements}

This study is a part of the Evidence-Based Forestry (EBF) initiative at CIFOR, funded through UK's Department for International Development (DfID). The authors thank the advisory group for their feedback on the protocol and the discussion at the stakeholder workshop at the launch of the review. Lastly, we thank two anonymous reviewers whose comments helped improve the research protocol.

\section{Author details}

${ }^{1}$ Forest Industries Research Centre, University of the Sunshine Coast, Maroochydore, QLD 4558, Australia. ${ }^{2}$ School of Agriculture and Food Sciences, The University of Queensland, St Lucia, QLD 4072, Australia. ${ }^{3}$ Centre for International Forestry Research, Bogor, Indonesia. ${ }^{4}$ Centre for Mined Land Rehabilitation, The University of Queensland, St Lucia, QLD 4072, Australia. ${ }^{5}$ School of Geography, University of Melbourne, Parkville, VIC 3010, Australia. ${ }^{6}$ School of Environment, Science and Engineering, Southern Cross University, Lismore, NSW 2480, Australia. ${ }^{7}$ School of Earth, Environmental and Biological Sciences, Queensland University of Technology, Brisbane, QLD 4001, Australia.

\section{Received: 17 September 2014 Accepted: 20 May 2015}

Published online: 01 July 2015

\section{References}

1. Lamb D. Regreening the Bare hills: Tropical Forest Restoration in the Asia-Pacific Region. Dordrecht: Springer; 2011.

2. Shepherd KR. Plantation Silviculture. Dordrecht: Martinus Nijhoff Publishers; 1986.

3. Carnus J-M, Parrotta J, Brockerhoff E, Arbez M, Jactel H, Kremer A, et al. Planted forests and biodiversity. J For. 2006;104:65-77.

4. Forrester DI, Bauhus J, Cowie AL, Vanclay JK. Mixed-species plantations of Eucalyptus with nitrogen-fixing trees: a review. For Ecol Manag. 2006;233:211-30.

5. Lamb D, Nhan HD, Erskine PD. Designing mixed-species plantations: Progress to date. In: Erskine PD, Lamb D, Bristow M, editors. Reforestation in the tropics and subtropics of Australia using rainforest tree species. An Australian Government Initiative; 2005:141 pp. 141.

6. Forrester DI. Mixed-species plantations of nitrogen-fixing and non-nitrogen-fixing trees, PhD. The Australian National University, School of Resources, Environment and Society. 2004.

7. Smith DM, Larson BC, Kelty MJ, Ashton PMS. The Practice of Silviculture: Applied Forest Ecology. 9th ed. New York: Wiley; 1997.

8. Montagnini F. Selecting Tree Species for Plantation. In: Forest Restoration in Landscapes. New York: Springer; 2005. p. 262-8.

9. Debell DS, Cole TG, Whitesell CD. Growth, development, and yield in pure and mixed stands of Eucalyptus and Albizia. For Sci. 1997:43:286-98.

10. Ewel JJ. Designing agricultural ecosystems for the Humid tropics. Annu Rev Ecol Syst. 1986:17:245-71.

11. Montagnini F, Jordan CF. Tropical Forest Ecology: The Basis for Conservation and Management. Dordrecht: Springer; 2005

12. Knoke T, Ammer C, Stimm B, Mosandl R. Admixing broadleaved to coniferous tree species: a review on yield, ecological stability and economics. Eur J For Res. 2008;127:89-101.

13. Binkley D, Dunkin K, Debell D, Ryan M. Production and nutrient cycling in mixed plantations of Eucalyptus and albizia in Hawaii. For Sci. 1992;38:393-408.
14. Forrester DI. Mixed-Species Plantations of Eucalyptus with Nitrogen-Fixing Trees. 2004.

15. Montagnini F. Accumulation in above-ground biomass and soil storage of mineral nutrients in pure and mixed plantations in a humid tropical lowland. For Ecol Manag. 2000;134:257-70.

16. FAO. Mixed and Pure Forest Plantations in the Tropics and Subtropics. In: FAO Forestry Paper, 152. Rome: FAO; 1992. p. 152.

17. Piotto D. A meta-analysis comparing tree growth in monocultures and mixed plantations. For Ecol Manag. 2008;255:781-6.

18. Kelty MJ. The role of species mixtures in plantation forestry. For Ecol Manag. 2006:233:195-204

19. Le HD, Smith C, Herbohn J, Harrison S. More than just trees: assessing reforestation success in tropical developing countries. J Rural Stud. 2012;28:5-19.

20. Kelty MJ. Comparative Productivity of Monocultures and Mixedspecies Stands. In: Kelty MJ, Larson BC, Oliver CD, editors. The Ecology and Silviculture of Mixed-Species Forests. Dordrecht, Boston: Kluwer Academic Publishers; 1992. p. 125-41.

21. Forrester DI, Bauhus J, Cowie AL. On the success and failure of mixed-species tree plantations: lessons learned from a model system of Eucalyptus globulus and Acacia mearnsii. For Ecol Manag. 2005;209:147-55.

22. Haggar JP, Ewel JJ. Primary productivity and resource partitioning in model tropical ecosystems. Ecology. 1997;78:1211-21.

23. Manson DG, Hanan J, Hunt M, Bristow M, Erskine PD, Lamb D, et al. Modelling predicts positive and negative interactions between three Australian tropical tree species in monoculture and binary mixture. For Ecol Manag. 2006;233:315-23.

24. Menalled FD, Kelty MJ, Ewel JJ. Canopy development in tropical tree plantations: a comparison of species mixtures and monocultures. For Ecol Manag. 1998:104:249-63.

25. Le HD, Smith C, Herbohn J. What drives the success of reforestation projects in tropical developing countries? The case of the Philippines. Glob Environ Chang. 2014;24:334-48

26. Higgs ES. What is good ecological restoration? Conserv Biol. 1997;11:338-48

27. Light A, Higgs ES. The politics of ecological restoration. Environ Ethics. 1996;18:227-47.

28. Swart JAA, Van Der Windt HJ, Keulartz J. Valuation of nature in conservation and restoration. Restor Ecol. 2001;9:230-8.

29. Herbohn KF, Harrison SR, Herbohn JL. Lessons from small-scale forestry initiatives in Australia: the effective integration of environmental and commercial values. For Ecol Manag. 2000;128:227-40.

30. Scopus. [http://www.scopus.com]

31. CABI. [http://www.cabdirect.org/].

32. Web of Science. [http://www.webofknowledge.com].

33. Agricola. [http://agricola.nal.usda.gov/]

34. GFIS.net. [http://www.gfis.net/gfis/en/en/]

35. Google Scholar. [http://scholar.google.com].

36. World Bank. [www.worldbank.org]

37. Asian Development Bank. [www.adb.org].

38. The Center for People and Forests. [www.recoftc.org]

39. Food and Agriculture Organization. [www.fao.org].

40. Tropenbos International. [www.tropenbos.org].

41. International Tropical Timber Organziation. [www.itto.int].

42. World Wildlife Fund. [www.worldwildlife.org].

43. French Agricultural Research Centre for International Development. [www.cirad.fr/en].

44. Tropical Agricultural Research and Higher Education Center. [http://www.catie.ac.cr/en/]

45. University of the Philippines, Los Banos. [www.uplbedu.ph]

46. Chiang Mai University. [www.cmu.ac.th/index_eng.php]

47. Center for International Forestry Research. [www.cifor.org]

48. World Agroforestry Centre. [www.worldagroforestry.org]

49. International Union of Forest Research Organizations. [www.iufro.org].

50. Small-scale Forestry Group. [http://www.iufro.org/science/divisions/ division-3/30000/30800/]

51. University of South Florida. [wwwesf.edu].

52. United States Department of Agriculture. [www.usda.gov]

53. ASB Partnership for the Tropical Forest Margins. [http://www.asb.cgiar.org/]

54. McHugh ML. Interrater reliability: the kappa statistics. Biochem Med (Zagreb). 2012:22(3):276-82

55. Fingerman S. Web of Science and Scopus: Current features and capacities. Issues in Science and Technology Librarianship. 2006:48(Fall). Retrieved from http://www.istl.org/06-fall/electronic2.html 